NASA Technical Memorandum 100431

\title{
Performance Improvements of an F-15 Airplane With an Integrated Engine-Flight Control System
}

Lawrence P. Myers and Kevin R. Walsh

(NASA-TH-100431) PERFORHANCE IMPROVEMENTS

N $88-21159$

OP AN F-15 AIERLANE NITH AN INTEGRATED

ENGINE-FLIGHT CONTROL SYSTEM (NASA) 12 p

$\begin{array}{lll}\operatorname{CSCL} 21 \mathrm{E} & & \text { Unclas } \\ & \mathrm{G} 3 / 07 & 0137313\end{array}$

May 1988

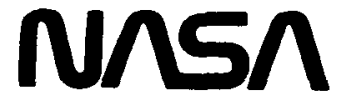

National Aeronautics and

Space Administration 
NASA Technical Memorandum 100431

\section{Performance Improvements of an F-15 Airplane With an Integrated Engine-Flight Control System}

Lawrence P. Myers and Kevin R. Walsh

Ames Research Center, Dryden Flight Research Facility, Edwards, California

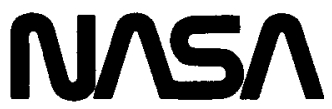

National Aeronautics and

Space Administration

Ames Research Center

Dryden Flight Research Facility

Edwards, California 93523-5000 
PERFORMANCE IMPROVEMENTS OF AN F-1S AIRPLANE WITH AN INTEGRATED ENGINE-FLIGHT CONTROL SYSTEM

Lawrence P. Myers and Kevin R. Walsh

NASA Ames Research Center

Dryden Flight Research Facility

Edwards, California

\section{Abstract}

An integrated flight and propulsion control system has been developed and flight demonstrated on the NASA Ames-Dryden F-15 research aircraft. The highly integrated digital control (HIDEC) system provides additional engine thrust by increasing engine pressure ratio (EPR) at intermediate and afterburning power. The amount of EPR uptrim is modulated based on airplane maneuver requirements, flight conditions, and engine information.

Engine thrust was increased as much as 10.5 percent at subsonic flight conditions by uptrimming EPR. The additional thrust significantly improved aircraft performance. Rate of climb was increased 14 percent at $40,000 \mathrm{ft}$ and the time to climb from 10,000 to $40,000 \mathrm{ft}$ was reduced 13 percent. A 14 and 24 percent increase in acceleration was obtained at intermediate and maximum power, respectively.

The HIDEC logic performed fault free. No engine anomalies were encountered for EPR increases up to 12 percent and for angles of attack and sideslip of $32^{\circ}$ and $11^{\circ}$, respectively.

\section{Nomenclature}

ADECS advanced engine control system

AJ exhaust nozzle area, $\mathrm{ft}^{2}$

alpha angle of attack, deg

beta sideslip angle, deg

CAS control augmentation system

D inlet distortion

DEEC diyital electronic engine control

DEFCS digital electronic flight control system

DFCC digital flight control computer

DFPR change in fan pressure ratio

EMD engine model derivative

EPR engine pressure ratio, PT6/PT2

EPRP engine pressure ratio for optimum performance

EPRS engine pressure ratio for maximum stability (minimum inlet distortion)

EPRUS engine pressure ratio at distortion other than minimum
EPRU EPR uptrim command implemented by DEEC

FNP net propulsive force, Ib

FPR fan pressure ratio, PT2.5/PT2

FPRS fan pressure ratio for maximum stability (minimum inlet distortion)

FPRUS fan pressure ratio at distortion other than minimum

FIIT fan turbine inlet temperature, ${ }^{\circ} \mathrm{F}$

HIDEC highly integrated digital control

INS inertial navigation system

KEPR cockpit multiplier on EPR command sent to engine DEEC

N1 fan speed, rpm

N1C2 corrected fan speed, rpm

PLA power lever angle, deg

Ps specific excess power, $\mathrm{ft} / \mathrm{sec}$

PS2 static pressure at fan inlet, psia

PT2 total pressure at fan inlet, psia

PT6 total pressure at turbine, psia

TSFC thrust specific fuel consumption

TT2 total temperature at fan inlet, ${ }^{\circ} \mathrm{F}$

UART universal asynchronous receiver transmitter

WA

corrected engine airflow, $1 \mathrm{~b} / \mathrm{sec}$

WACC corrected fan airflow, Ib/sec

$\alpha \quad$ angle of attack, deg

$B \quad$ angle of sideslip, deg

$\Delta \quad$ incremental change

\section{Int roduction}

Substantial performance gains can be obtained by integrating the flight and propulsion control systems. 1 By using the high throughput and large memory of current onboard computers, along with high-speed communication data buses, it will be possible to implement a wide range of integrated flight and propulsion control modes onboard future aircraft. Such modes will increase total vehicle 
effectiveness without significant weight or cost penalties. Independent optimization of each control system is usually compromised by worst case assumptions of other systems. To investigate the problem associated with integration and to quantify the performance benefits, NASA Ames Research Center's Dryden Flight Research Facility is conducting a program called highly integrated electronic control (HIDEC). One feature in the HIDEC program is the advanced engine control system (ADECS).2

In a conventional engine control system, the engine stall margin is large enough to accommodate the worst case combination of engine and airplane induced disturbances. In the ADECS, the stall margin is modulated in real time based on the current engine and aircraft requirements and flight conditions. This permits the unneeded stall margin to be traded for increased engine performance by increasing thrust, reducing fuel flow, or lowering operating temperatures. The exchange between unneeded engine stall margin and increased engine performance is implemented by uptrimming the engine pressure ratio (EPR). The performance benefits obtained by reducing engine stall margin were predicted and presented by Burcham and others. 3

A flight evaluation of the ADECS feature was conducted at the Ames-Dryden Flight Research Facility on an F-15 airplane. An evaluation of the performance of the F-15 aircraft with one engine equipped with a HIDEC system was presented by Myers and Walsh. 4

This paper presents results of the evaluation with two HIDEC engines, the ADECS system description, flight test procedures, engine thrust gains, and aircraft performance improvements.

\section{System Description}

\section{Airplane}

The NASA F-15 airplane is being used for the HIDEC program. The F-15 is a high-performance air superiority fighter with excellent transonic maneuverability and has a maximum Mach number capability of 2.5. It is powered by two afterburning turbofan engines.

\section{Engine}

The $F 100$ engine model derivative (EMD) engines ${ }^{5}$ are an upgraded version of the F100-PW-100 engine that currently powers the production $F-15$ airplanes. These two engines were built by Pratt and Whitney (West Palm Beach, Florida) and have a company designation of PW 1128. The engines incorporate a redesigned fan, revised compressor and combustor, single crystal turbine blades and vanes, a 16-segment augmentor with lightoff detector, and a digital electronic engine control (DEEC).

The DEEC, as discussed by Burcham and others, 6 is a key part of the HIDEC system. It is a fullauthority digital control with an integral hydro- mechanical backup control. It controls the gas generator and the augmentor fuel flows, compressor bleeds, variable inlet guide vanes, variable stators, and the variable exhaust nozzle. The DEEC logic provides closed loop control of corrected fan airflow (WACC) and engine pressure ratio (EPR). It also limits fan turbine inlet temperature (FTIT). It has been modified for the HIDEC program to accept inputs from the airplane.

\section{HIDEC System}

The equipment and features used for the HIDEC program 7 are shown in Figs. 1 and 2. The two main features of the HIDEC program were the DEEC engine controller and the digital electronic flight control system (DEFCS). The DEFCS is a digital implementation of the analog control augmentation system (CAS) and has the same flight control authority as the analog CAS. The DEFCS communicates with the DEEC through a digital interface and bus control unit. The pilot makes inputs to the HIOEC system using the cockpit control and display units. The ADECS uptrim control law software is in the digital flight control computer (DFCC) which is part of the DEFCS.

A block diagram of the HIDEC system on the $\mathrm{F}-15$ is shown in Fig. 2. The various digital systems on the airplane use three separate data buses to communicate with each other through a digital interface and bus controller. This unit permits the HIDEC system to communicate with the F-15 Houg data bus, the universal asynchronous receiver transmitter (UART) data bus from the DEEC, and the MIL-STU-1553A flight control data bus. The normal throttle inputs from the cockpit to the DEEC controller and the backup engine control are maintained.

An ADECS block diagram is shown in Fig. 3. The airplane data is used to estimate the angles of attack $(\alpha)$ and sideslip ( $\beta)$. This information, along with the corrected engine airflow (WA), allows the calculation of inlet distortion (D) and the amount of incremental change in engine pressure ratio for maximum stability uptrim ( $\triangle E P R S)$. Another calculation uses engine parameters to determine the amount of engine pressure ratio for optimum performance ( $\triangle E P R P$ ). The lower value of the two EPR uptrim commands, with a pilot selectable EPR multiplier (KEPR), is then sent to the DEEC which implements the uptrim on the engine. The DEEC also contains an upper limit of allowable uptrim for safety.

The amount of EPR uptrim allowable depends on the available excess stall margin of the engine. The F-15/F100 EMD engine combination has substantial excess stall margin at moderate inlet distortion levels. The stall margin allowance for normal engine operation is shown in Fig. 4 and consists of the following: engine to engine allowances for the manufacturing tolerance in building the engine, engine control tolerance allowance, Reynolds number (altitude) effects, inlet distortion allowance for maneuvering up to extreme angles of attack and sideslip, allowance for lighting and cancelling the augmentor segments, and any remaining allowance for uncertainty. 
The stall margin available during ADECS operation, also shown in Fig. 4, consists of the same engine to engine, control system, and Reynolds number allowances as for normal operation. With ADECS, however, the inlet distortion allowance is reduced to the amount required for the current aircraft attitude and flight condition, as opposed to the worst case condition. The augmentor sequencing allowance is used at intermediate and maximum power, but is not used during partial afterburning. In most cases, this excess stall margin available for uptrim is about 11 to 13 percent, depending on flight condition. An arbitrary 4 percent remaining stall margin for uncertainty was retained.

\section{Engine Pressure Ratio Uptrim Logic}

The EPR uptrim logic resides in the digital flight control computer (DFCC) and determines the proper EPR command to send the DEEC to obtain higher thrust. 8 To accomplish this, two EPRs are calculated: the optimum performance EPR and the limiting stability EPR which accounts for inlet distortion. The lower of these two values is selected as the HIDEC uptrim EPR. This command is passed to the DEEC as a percentage where it is checked for validity against the DEEC EPR limit. Figure 5 shows the HIDEC EPR uptrim concept on a typical fan map. The stall line is shown as the upper limit. The distance between the stall line and the normal operating line represents the stall margin available. The DEEC EPR limit represents the maximum EPR allowed by the DEEC during uptrim. The stability EPR considers all destabilizing factors that reduce the fan stall margin from the basic steady-state level. As inlet distortion increases, the stability EPR adjusts downward to maintain an adequate stall margin. The optimum performance EPR does not take stall margin into account. It represents the optimum EPR based on predicted thrust gains.

EPR is first increased along a constant corrected fan speed line up to a fan turbine inlet temperature (FTIT) limit. Upon reaching the FTIT limit, EPR is then uptrimmed along the maximum FTIT limit line. Uptrim along the FTIT limit produces a small additional benefit before thrust begins to decrease because of the reduction in engine airflow. During EPR uptrim, the fan operates closer to the stall line. Therefore, excess fan stall margin, not required for inlet distortion, is traded for additional thrust.

The DEEC responds to the uptrim request by closing the nozzle until the desired EPR is reached. The increase in EPR results in an increase in engine thrust. The uptrim logic is limited to power settings at which the EPR control loop is active, above $70^{\circ}$ power lever angle (PLA). When uptrim is requested, the DEEC ramps in the uptrim value over a period of $1 \mathrm{sec}$. This allows for smooth transition to uptrim operation.

A flow diagram of the EPR uptrim logic in the DFCC is shown in Fig. 6. The blocks illustrate schedules and calculations while the arrows indicate the flow of input data.
Optimum Performance EPR

The engine pressure ratio for optimum performance (EPRP) represents EPR at which optimum engine thrust was obtained. It was scheduled as a function of corrected fan speed (NIC2) and total pressure at fan inlet (PT2), as shown in block 1 of Fig. 6. The schedule was determined from extensive simulation data and denotes the most desirable EPR from a performance standpoint. This data was obtained by using the steady-state engine simulation at a variety of flight conditions. The EPR was increased incrementally for each condition until the peak thrust was reached. This corresponded with the optimum performance EPR.

Although the optimum performance EPR is the most desirable in terms of engine performance, it is often unattainable due to stability considerations and protective limits in the DEEC.

\section{Stability EPR}

An EPR based on engine stability, which accounts for inlet distortion, was calculated to limit the amount of uptrim during conditions of reduced fan stall margin due to inlet distortion. Inlet distortion increases at low Mach numbers, for reduced inlet airflows, and at high angles of attack or sideslip. Because of this complex relationship, the uptrim stability logic required input from both aircraft and engine parameters to calculate the stability EPR limit.

The stability logic begins in block 2, Fig. 6 , by calculating the inlet distortion factor based on aircraft and engine conditions. The inlet distortion factor was obtained by calculating a base distortion factor for the current Mach number and predicted angle of attack. This base value was corrected for effects of sideslip and engine airflow.

The change in fan pressure ratio (DFPR), based on the stall margin sensitivity to the calculated distortion factor, was also calculated in block 2. First, the difference between the calculated distortion factor and the scheduled minimum distortion factor was determined. The minimum distortion factor was scheduled from the current flight Mach number. This differential value of inlet distortion was multiplied by the stall margin sensitivity factor to determine the current sensitivity of stall margin to distortion.

The stability logic used the change in fan pressure ratio to adjust the fan pressure ratio for maximum stability (FPRS). The FPRS was computed in block 3 from the maximum stability engine pressure ratio. The resulting difference between FPRS and DFPR yielded the adjusted maximum stability fan pressure ratio (FPRUS). This value was converted back to an engine pressure ratio, as shown in block 4 . The result was the limiting stability engine pressure ratio (EPRUS) based on distortion. The minimum was selected beween EPRUS and EPRP, resulting in the uptrim command EPRU.

Figure 7 shows how the EPR control loop was implemented in the DEEC logic. The EPR uptrim 
logic resided in the DFCC and determined the proper EPR command to send to the DEEC. In the nonuptrimmed and uptrimmed modes, exhaust nozzle area (AJ) was used to maintain a desired EPR. At high Mach numbers, if the gas generator was operated on the FTIT limit, control was switched to corrected fan speed (NIC2) to protect the inlet minimum airflow and to optimize net propuisive force. The DEEC controlled EPR only between $70^{\circ}$ PLA and maximum power settings. From idle to $70^{\circ}$ PLA, nozzle area was set to a fixed value. The scheduled EPR was determined as a function of corrected fan rotor speed (N1C2) and calculated engine inlet total pressure (PT2). The EPR was then maintained by varying the exhaust nozzle area by means of a proportional plus integral controller to trim a basic schedule. The basic schedule was a function of augmentor fuel-air ratio, total temperature at fan inlet (TT2), and PT2. The PT2 was obtained by multiplying the engine inlet static pressure (PS2) sensed by the engine noseboom probe, by the total-to-static pressure ratio defined as a function of NIC2 and PS2. During partial afterburning power, 6 percent was substracted from the uptrim command to allow for afterburner light off and segment sequencing. The DEEC scheduled EPR was multiplied by the EPR command from the DFCC as shown in Fig. 7.

\section{Flight Test Procedures}

Thirty flights have been flown to assess engine and airplane performance. Intermediate and maximum power constant altitude accelerations were conducted between 10,000 and $50,000 \mathrm{ft}$. Six intermediate power climbs were completed from 10,000 to $40,000 \mathrm{ft}$ at airspeeds of 250 and 350 knots, and two intermediate power climbs were accomplished from 30,000 to $50,000 \mathrm{ft}$ at Mach 0.9 .

To minimize the required corrections for differences in ambient temperatures and aircraft gross weight, the aircraft accelerations and climbs were flown back-to-back, first with ADECS off and then repeated with ADECS on. Upon completion of the ADECS-off maneuver, the pilot would return to approximately the same location and fly the ADECS-on maneuver through approximately the same air mass.

\section{Advanced Engine Control System Flight Results}

\section{Engine Performance Improvements}

Figure 8 shows the percent improvement in net propulsive force (FNP) for constant altitude accelerations with intermediate power. The data is corrected to standard day conditions. The maneuvers were flown back-to-back with ADECS off and then repeated with ADECS on to minimize the corrections for ambient temperature and pressure. Constant altitude aircraft accelerations were accomplished at $10,000,20,000,30,000$, and $40,000 \mathrm{ft}$. Thrust improvements were calculated from the in-flight thrust deck and ranged from about 8 percent at 10,000 ft to 10.5 percent at $30,000 \mathrm{ft}$. These 8 to 10.5 percent improvements in thrust were larger than the 5 to 8 percent thrust improvements predicted by Myers and Burcham. 5
Another benefit from trading excess stall margin for increased performance is to reduce the thrust specific fuel consumption (TSFC) at constant thrust. Figure 9 shows the percent TSFC reduction with ADECS on for a constant thrust. At $30,000 \mathrm{ft}$, Mach 0.6, and maximum power, a 16 percent reduction in TSFC was shown. This compares well with the 17 percent reduction in TSFC predicted by Myers and Burcham. ${ }^{5}$ Similar results were obtained at Mach 0.9 and 1.2 at $30,000 \mathrm{ft}$. At Mach 0.9 , an 11 percent reduction in TSFC was demonstrated as compared to the 9 percent predicted reduction. 5

\section{Aircraft Performance Improvements}

The additional thrust obtained with EPR uptrim was effective in improving aircraft performance. When angle of attack is low at this condition, the uptrim command is maximized because the inlet distortion is low. The improvement in engine and aircraft performance during a constant altitude accleration at maximum power at $50,000 \mathrm{ft}$ is shown in Fig. 10. The time to accelerate from Mach 0.8 to 1.5 is 24 percent faster with the ADECS on. Figure 11 shows the improvement in specific excess power (Ps) with ADECS on for this acceleration. The gain in Ps ranged from about 10 percent at Mach 0.8 to 45 percent at Mach 1.5. The data was corrected for differences in aircraft gross weight during the accelerations.

Figure 12 shows an intermediate power, $40,000 \mathrm{ft}$, constant altitude acceleration from Mach 0.6 to 0.95 . With ADECS on, a 14 percent improvement in time to accelerate was demonstrated. Specific excess power with ADECS on was improved by 24 percent at Mach 0.9 .

The effect of EPR uptrim on a 350 knot, intermediate power climb from 10,000 to $40,000 \mathrm{ft}$ is shown in Fig. 13. EPR uptrim produced a significantly higher rate of climb at all altitudes, with a 14 percent improvement at $40,000 \mathrm{ft}$. With EPR uptrim, the time to climb from 10,000 to $40,000 \mathrm{ft}$ was reduced 13 percent. The data was corrected for aircraft gross weight differences.

Table 1 summarizes the improvement in F-15 aircraft climb performance with two ADECS engines installed and operating at intermediate power. Table 2 summarizes the improvement in F-15 aircraft acceleration performance with two ADECS engines.

Intentional in-flight engine stalls were generated by increasing the EPR command to high values to permit the methodology used in the stall margin calculation to be validated. A stall margin audit of an engine stall at Mach 0.6 and $30,000 \mathrm{ft}$ is shown in Fig. 14. The figure is an enlarged fan map, representing fan pressure ratio versus corrected air flow. The hashed upper line is the undistorted fan stall line with no inlet pressure distortion. The figure shows the allowance for distortion and also indicates the predicted average engine stall point with distortion based on wind tunnel data. Also shown for reference are the plus and minus two-sigma range for engine-to-engine differences and control toler- 
ances. The predicted stall point is less than 1 percent from the actual engine stall point, which gives credibility to the stall margin audit methodology.

\section{Concluding Remarks}

ADECS is the first integrated flight and propulsion control system to be demonstrated in flight on an aircraft specifically configured for integrated controls research. Engine thrust was increased as much as 11 percent at subsonic flight conditions by uptrimming EPR. The additional thrust significantly improved aircraft performance. Rate-of-climb was increased 14 percent at $40,000 \mathrm{ft}$ and the time-to-climb from 10,000 to $40,000 \mathrm{ft}$ was reduced 13 percent. A 14 and 24 percent increase in constant altitude acceleration was obtained at intermediate and maximum power, respectively.

Thirty flight tests have been flown. The ADECS uptrim logic was demonstrated successfully in flight tests over the F-15 flight envelope. The ADECS logic successfully accommodated extreme airplane manuevers and rapid throttle transients. Intentional stalls were generated by increasing the KEPR (cockpit adjustable multiplier) to high values (approximately two times nominal) to permit the methodology used in the stall margin calculations to be valiaated. Substantial thrust increases and fuel flow reductions were obtained, as well as significant improvements in aircraft performance during aircraft accelerations and climbs.

By using the high throughput and large memory of current onboard computers, along with highspeed communication data buses, it will be possible to implement a wide range of integrated flight and propulsion control modes onboard future aircraft. Such modes will increase total vehicle effectiveness without significant weight or cost penalties.

\section{References}

1Myers, L.P.; and Burcham, F.W., Jr.: Propulsion Control Experience Used in the Highly Integrated Digital Electronic Control (HIUEC) Program. NASA TM-85914, 1984.

2Burcham, F.W., Jr.; and Haering, E.A., Jr.: Highly Integrated Digital Engine Control System on an F-15 Airplane. NASA TM-86040, 1984.

3Burcham, F.W., Jr.; Myers, L.P.; and Ray, R.J.: Predicted Performance Benefits of an Adaptive Digital Engine Control System on an F-15 Airplane. AIAA 85-0255, Jan. 1985.

4Myers, L.P.; and Walsh, K.R.: Preliminary Flight Results of an Adaptive Engine Control System on an F-15 Airplane. AIAA 87-1847, June 1987.

5Myers, L.P.; and Burcham, F.W., Jr.: Preliminary Flight Test Results of the F100 EMD Engine in an F-15 Airplane. AIAA 84-1332, June 1984 .

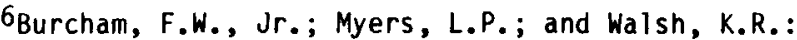
Flight Evaluation Results for a Digital Electronic Engine Control in an F-15 Airplane. NASA TM-84918, 1983.

7Landy, R.J.; Yonke, W.A.; and Stewart, J.F.: Development of HIDEC Adaptive Engine Control Systems. ASME 86-GT-252, June 1986.

8Ray, R.J.; and Myers, L.P.: Test and Evaluation of the HIDEC Engine Uptrim Algorithm. AIAA 86-1676, June 1986.

TABLE 1. - IMPROVEMENT IN F-15 CLIMB PERFORMANCE WITH ADECS AT INTERMEDIATE POWER

\begin{tabular}{lccc}
\hline \hline Altitude, ft & $\begin{array}{c}\text { Time-to-climb } \\
\text { improvement, } \%\end{array}$ & $\begin{array}{c}\text { Rate-of-climb } \\
\text { improvement, } \%, \\
\text { at altitude, ft }\end{array}$ & Airspeed \\
\hline $10,000-40,000$ & 15 & 28 at 30,000 & 250 knots \\
$10,000-40,000$ & 13 & 14 at 40,000 & 350 knots \\
$30,000-50,000$ & 30 & 76 at 50,000 & Mach 0.9 \\
\hline
\end{tabular}


TABLE 2. - IMPROVEMENT IN F-15 AIRCRAFT ACCELERATION PERFORMANCE WITH ADECS

\begin{tabular}{|c|c|c|c|c|}
\hline $\begin{array}{c}\text { Alt itude, } \\
\mathrm{ft}\end{array}$ & $\begin{array}{l}\text { Power } \\
\text { setting }\end{array}$ & Mach range & $\begin{array}{l}\text { Acceleration time } \\
\text { improvement, } \%\end{array}$ & $\begin{array}{l}\text { Specific excess power } \\
\text { (Ps) improvement, } \\
\text { \& \& Mach no. }\end{array}$ \\
\hline 10,000 & Int & $0.4-0.9$ & 5 & 1900.9 \\
\hline & $\operatorname{Max}$ & $0.4-0.9$ & 7 & 400.9 \\
\hline 20,000 & Int & $0.4-0.9$ & 2 & 900.9 \\
\hline & $\operatorname{Max}$ & $0.4-0.9$ & 8 & 400.9 \\
\hline 30,000 & Int & $0.5-0.9$ & 11 & 1300.9 \\
\hline & $\operatorname{Max}$ & $0.5-1.5$ & 24 & 2300.9 \\
\hline 40,000 & Int & $0.6-0.9$ & 14 & 1400.9 \\
\hline & $\operatorname{Max}$ & $0.6-1.5$ & 13 & 2000.9 \\
\hline 50,000 & $\operatorname{Max}$ & $0.8-1.5$ & 24 & $45 \bigcirc 1.5$ \\
\hline
\end{tabular}

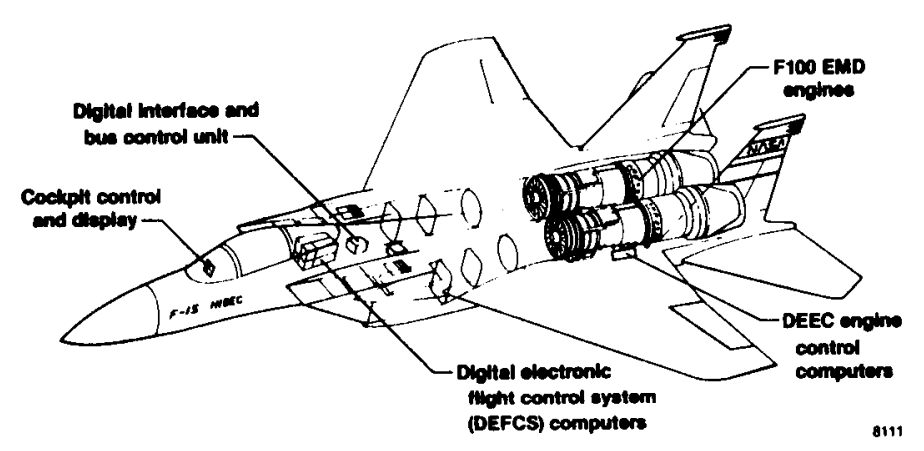

Fig. 1 Eeatures of the $F-15$ research airplane.

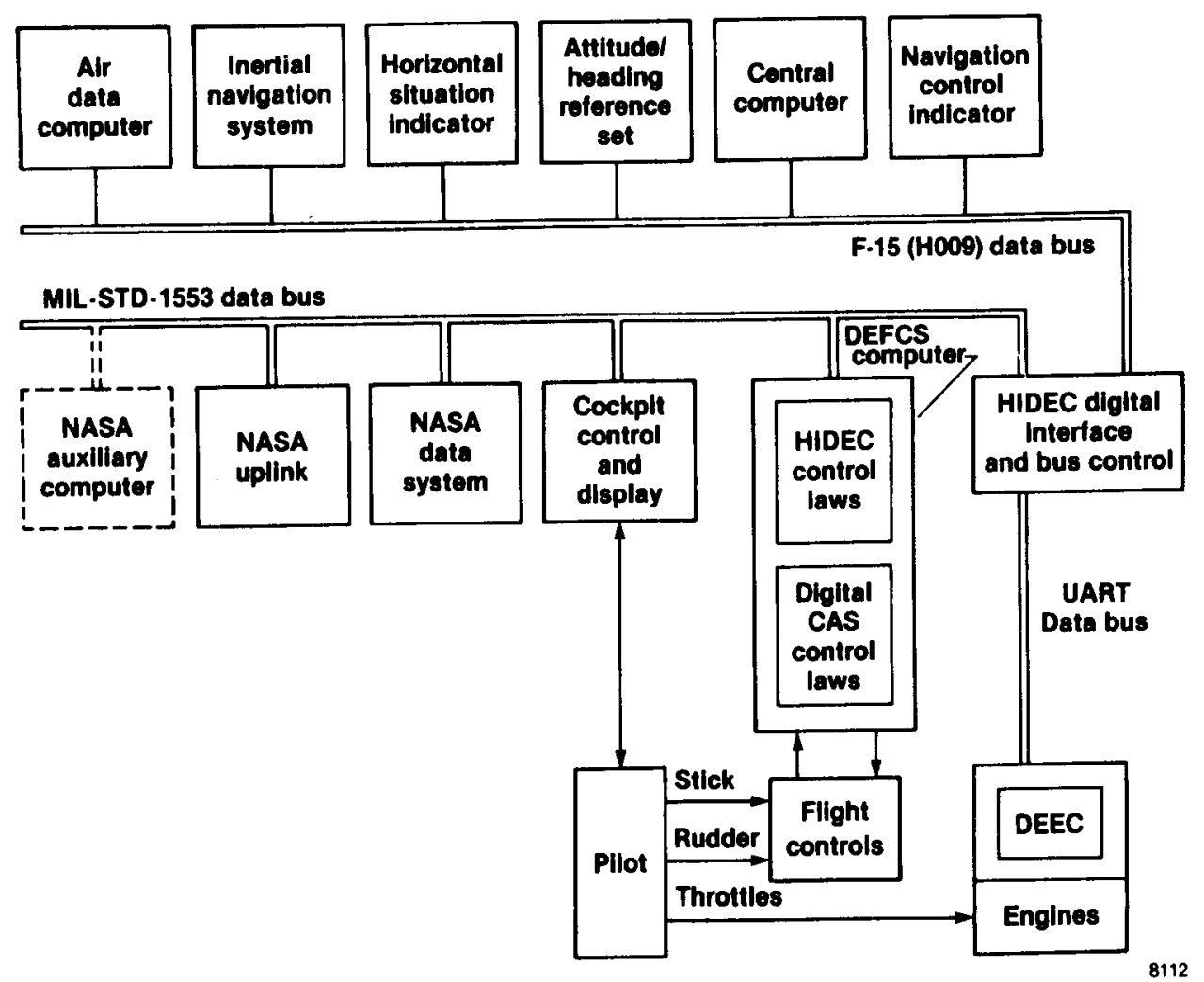

Fig. 2 Blook diagram of the BIDEC system. 


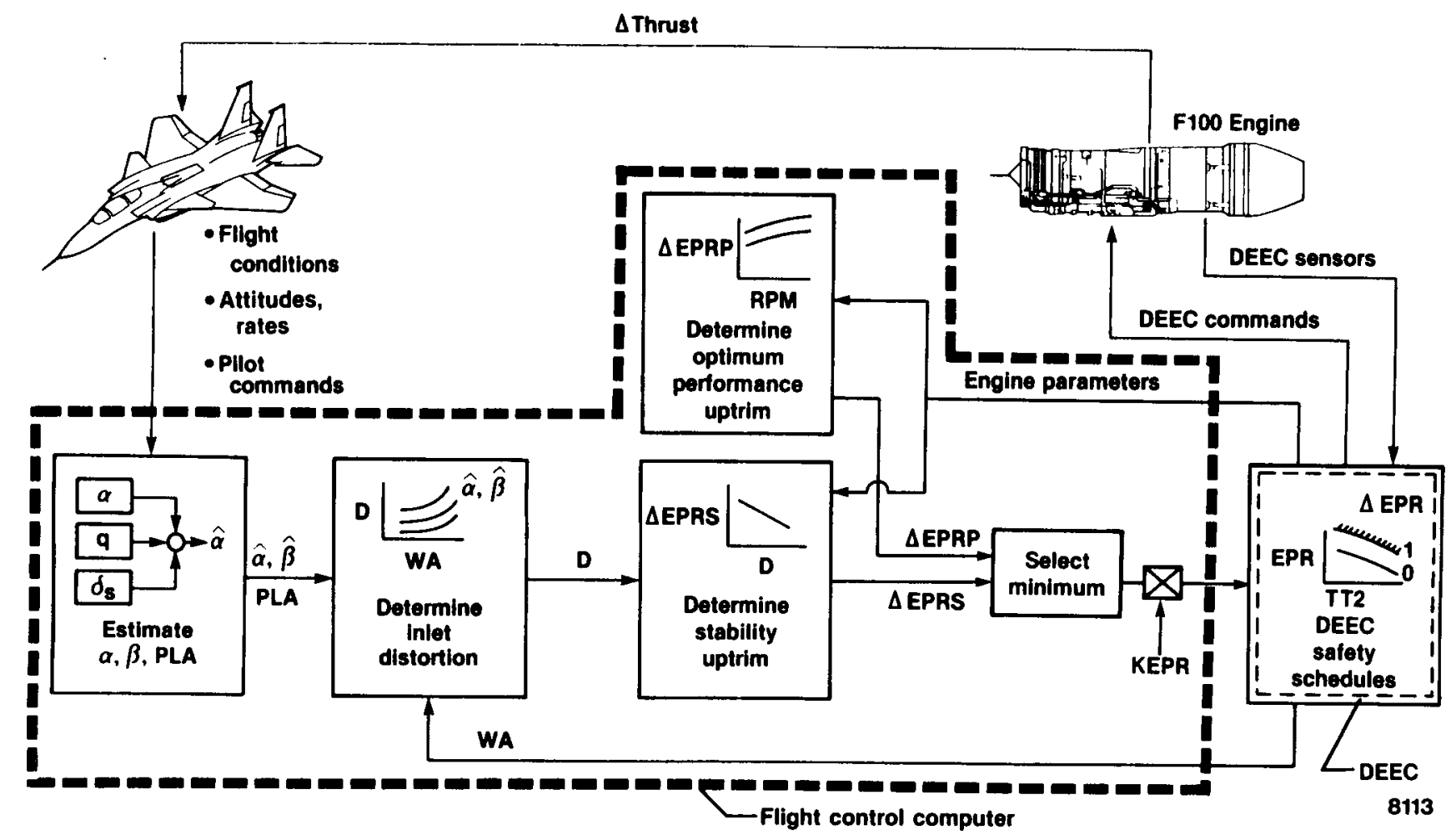

Fig. 3 Block diagram of the advaneed engine control system.

Without EPR uptrim

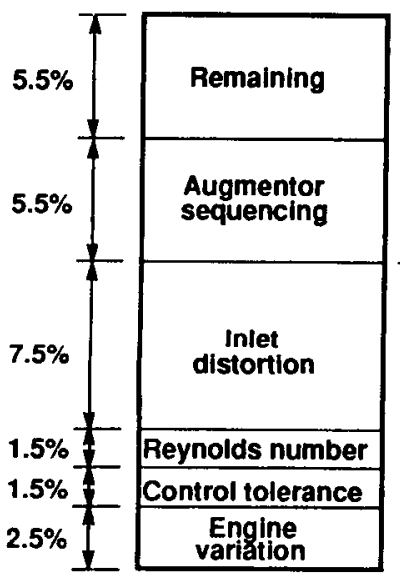

With EPR uptrim

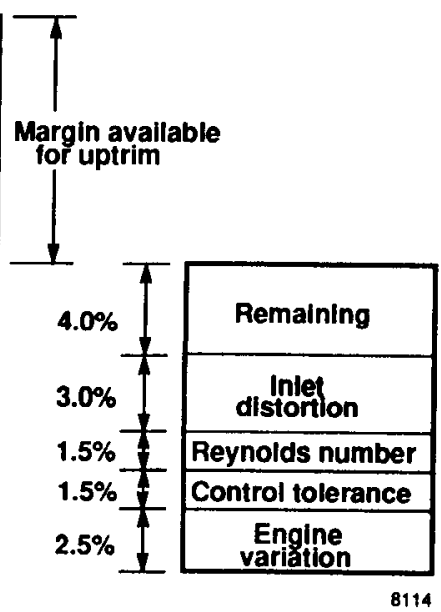

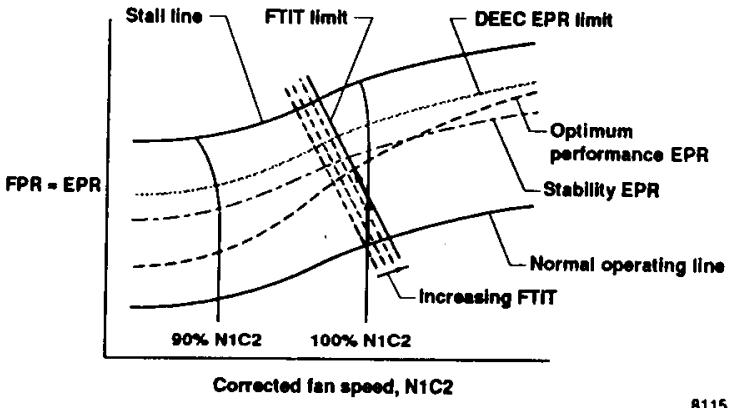

Fig. 5 Engine pressure ratio uptrin concept.

Fig. 4 Stall margin available. 


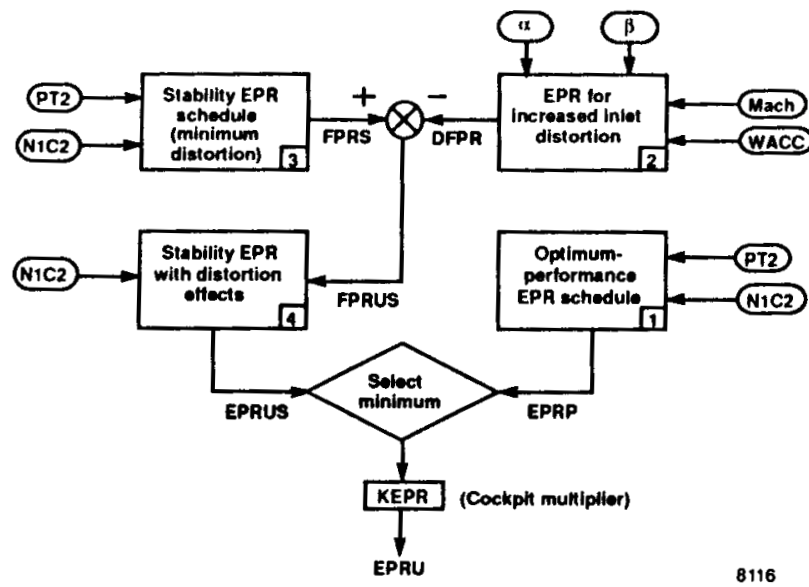

Fig. 6 Engine preseure ratio uptrim Logio in the digital flight control oomputer.

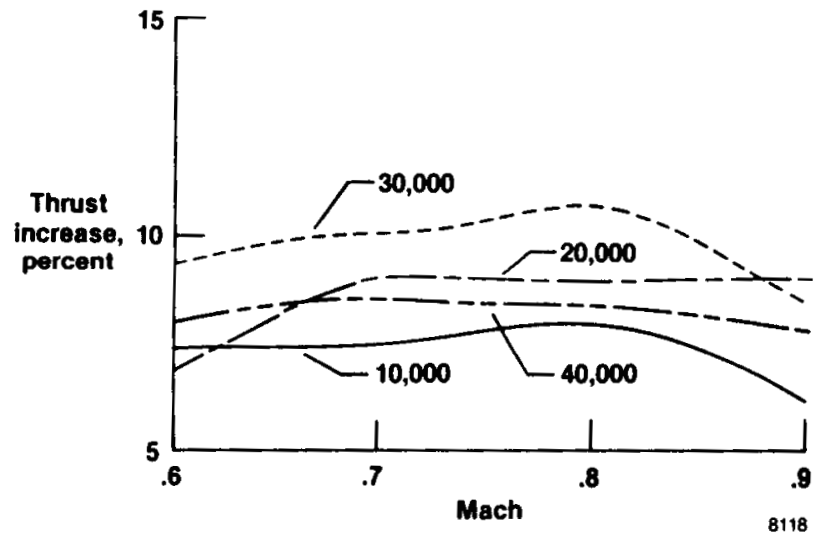

Fig. 8 Percentage improvement in thrust for intermediate power at various altitudes.

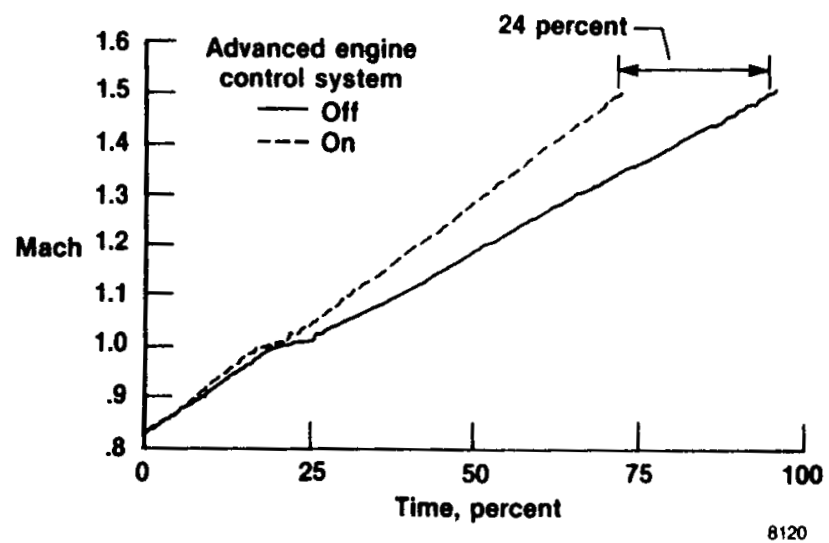

Fig. 10 Narimum power of airoraft acceleration at $50,000 \mathrm{ft}$.

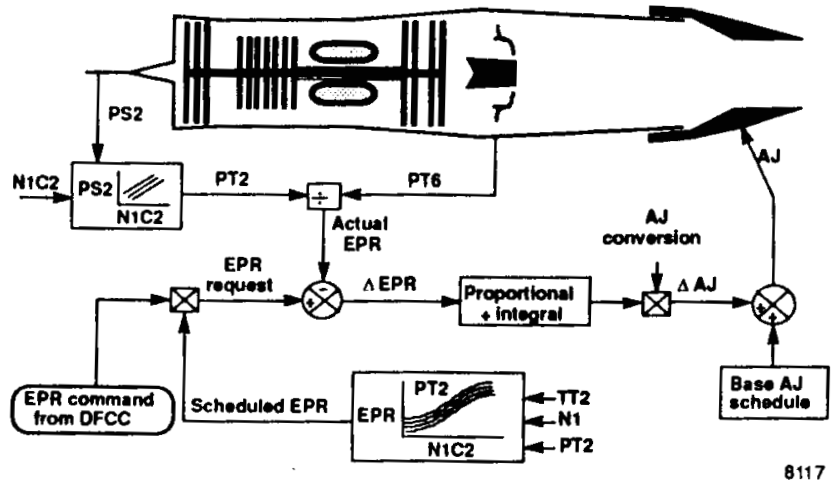

Fig. 7 Digital eleatronic engine control (DEEC) closed loop control of engine preseure ratio (EPR).

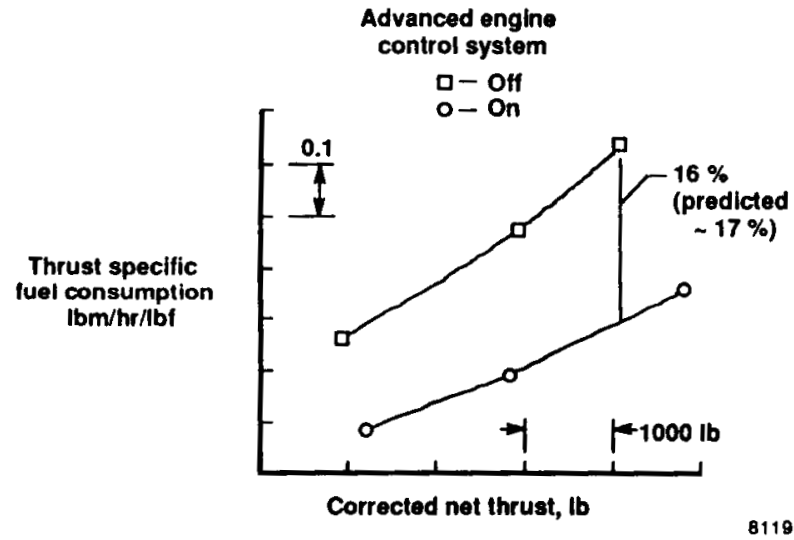

Fig. \& Poroentage raduotion in thruet opeoifio fuel consumption for aftarbuming power at Naoh 0.6 and $30,000 \mathrm{ft}$.

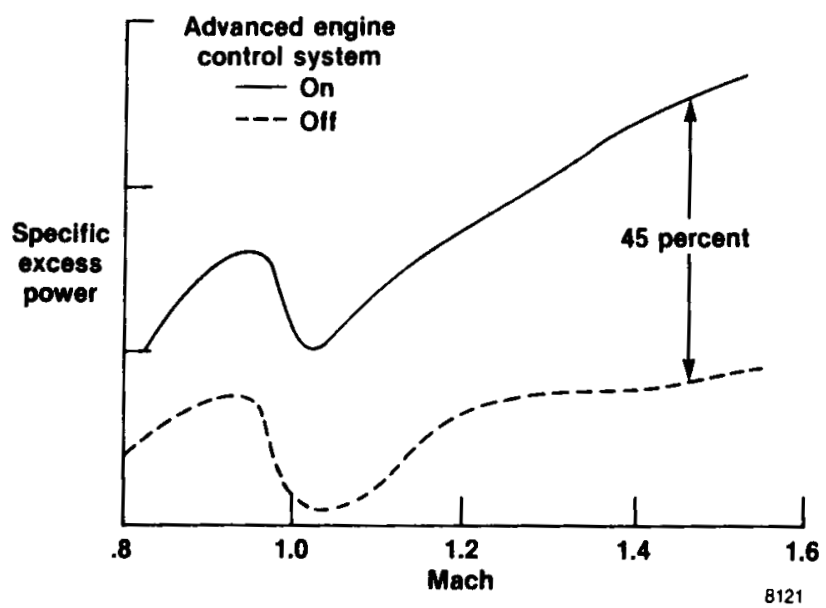

Fig. 11 Specific excess power improvement for maximum power of airoraft acceleration at $50,000 \mathrm{ft}$. 


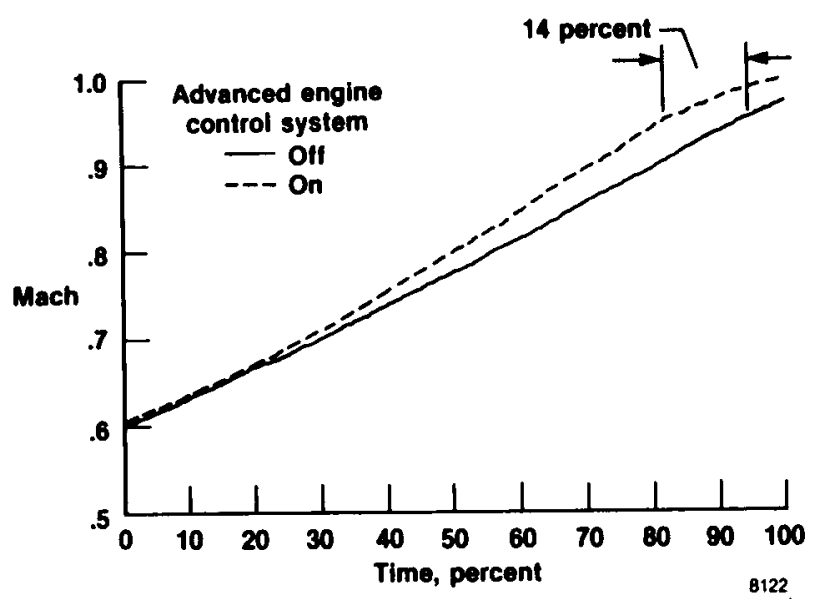

Fig. 12 Intermediate power of airoraft acoeleration comparison at $10,000 \mathrm{ft}$.

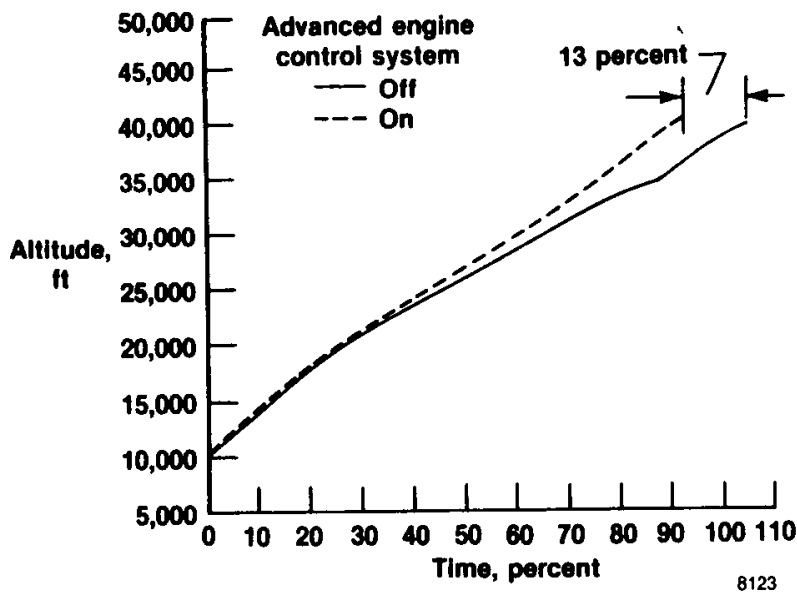

Fig. 13 Intermediate power alimb from 10,000 to $40,000 \mathrm{ft}$ at 350 knots.

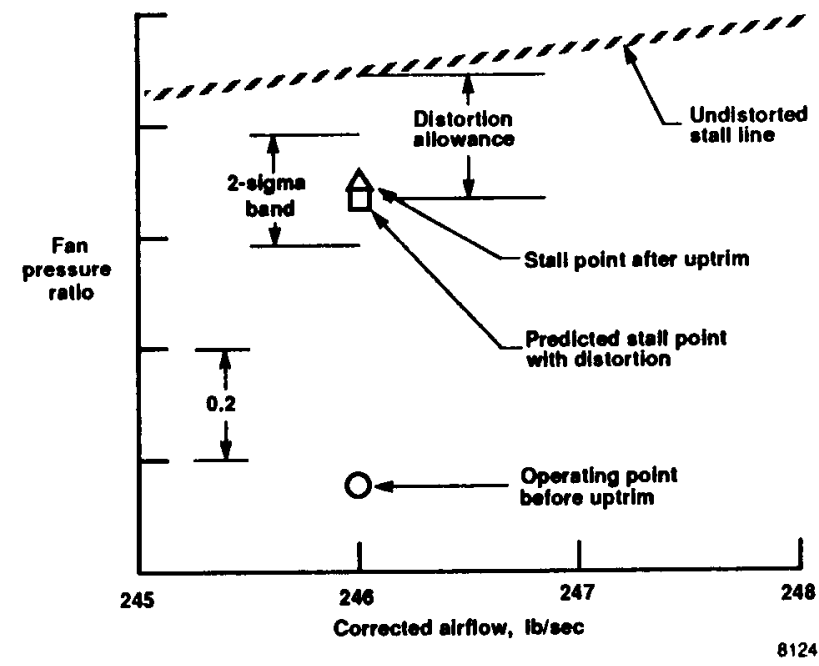

Fig. 14 Stall mangin audit of intentional in-flight engine stall at Naoh $0.6,30,000 \mathrm{ft}$ and maximum power. 


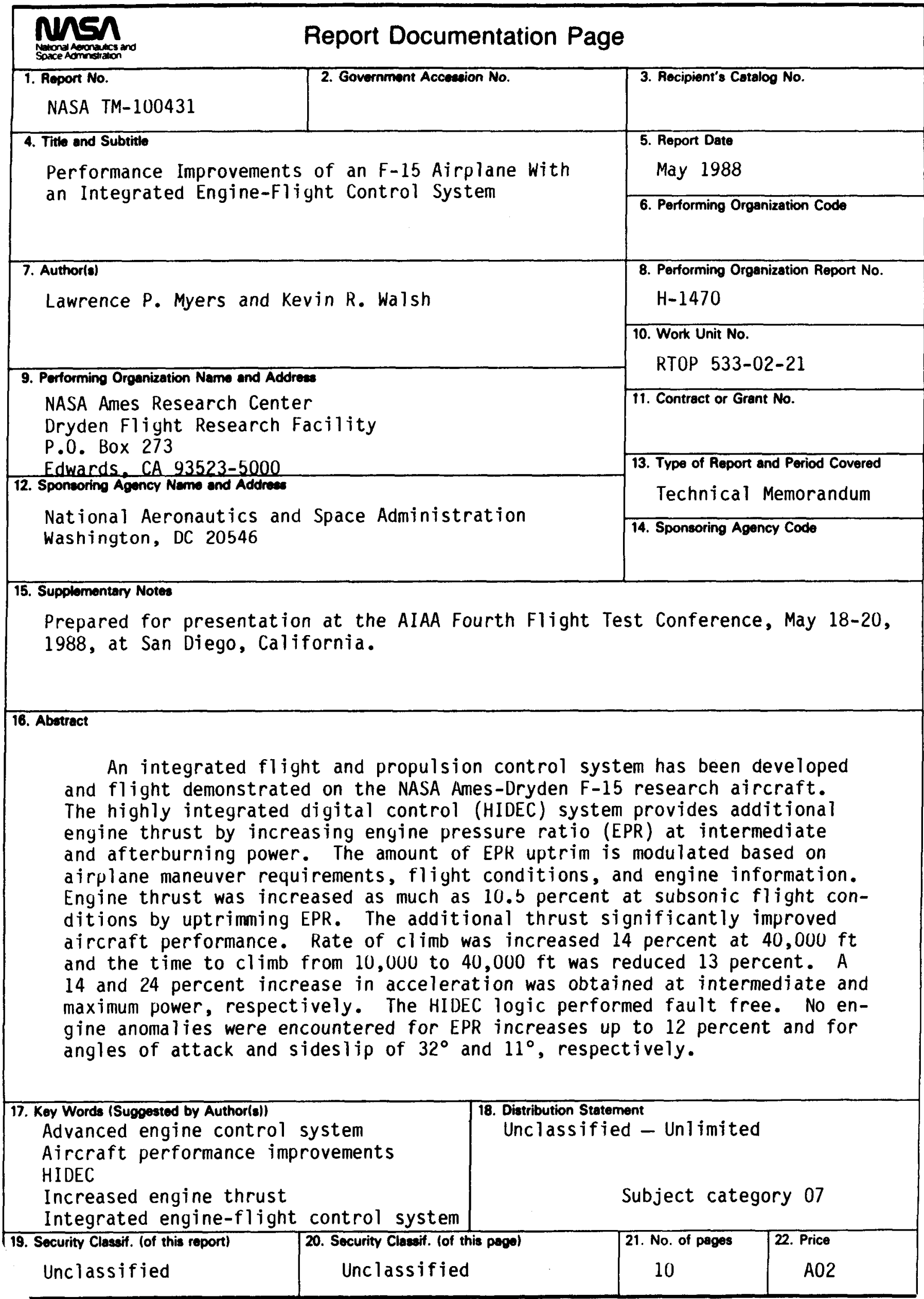

